\title{
Kahler's Disease with a Rare Clinical form and Review of Literature
}

\author{
R. D. Gogoua, D. G. Gogoua, M. Kaba \\ Maitre de Conférence Agrégé, Service d'Orthopédie Traumatologie, Abidjan, Ivory Coast \\ Email:gogouad@yahoo.fr
}

How to cite this paper: Gogoua, R.D., Gogoua, D.G. and Kaba, M. (2018) Kahler's Disease with a Rare Clinical form and Review of Literature. Open Journal of Orthopedics, 8, 39-45.

https://doi.org/10.4236/ojo.2018.82005

Received: December 29, 2017

Accepted: February 8, 2018

Published: February 11, 2018

Copyright $\odot 2018$ by authors and Scientific Research Publishing Inc. This work is licensed under the Creative Commons Attribution International License (CC BY 4.0).

http://creativecommons.org/licenses/by/4.0/

(c) (i) Open Access

\begin{abstract}
Kahler's disease or "multiple myeloma" is a cancerous disease of the bone marrow. It may appear straightaway in its multiple myeloma form or in the form of solitary bone plasmacytoma or extra bone plasmacytoma. In the extra bone form, its orbital location as the first symptom is exceptional. Our case concerned a 49-year-old female patient without significant medical history who was followed for 6 months for a voluminous left exophthalmos. This ocular symptomatology was accompanied six months after by acute bone pains in the spine and pelvis then by a pathological fracture of the left trochanter. Histological assessment during the treatment showed the diagnosis of Kahler's disease. The serum calcium was $106 \mathrm{mmol} / \mathrm{l}$, a blood level of chloride to $96 \mathrm{mmol} / \mathrm{l}$, of potassium to $5.36 \mathrm{mmol} / \mathrm{l}$, of sodium to $136 \mathrm{mmol} / \mathrm{l}$. The 24-hour proteinuria was $0.30 \mathrm{~g} / \mathrm{l}$ and indicated renal impairment. The patient had anemia with a hemoglobin level to $8.8 \mathrm{~g} / \mathrm{l}$. Tumor markers were normal; in particular the CA was 13.148 , ACE-2 to $1.013 \mathrm{ng} / \mathrm{ml}$ and CA19-9 to 5.029 $\mathrm{IU} / \mathrm{ml}$. The patient was transferred to a specialized unit but died before the start of treatment. Thus any isolated exophthalmos or accompanied by bone signs must systematically suggest Kahler's disease and make undertake investigations in this direction. It is on this condition that an early management of the disease can improve the prognosis of the disease and prolong the patient's life.
\end{abstract}

\section{Keywords}

Kahler's Disease, Plasmacytoma, Orbital Location of

\section{Introduction}

Kahler's disease or "multiple myeloma" is a cancerous disease of the bone marrow caused by the proliferation of plasma cells, specialized cells in the produc- 
tion of immunoglobulins. It can take various clinical forms and the most common symptoms are represented by bone pain and spontaneous fractures [1] [2]; sometimes an anemia or repeated infections, in particular lung. This pathology most commonly affects people over 50 years and is more common in men than in women [2] [3].

The Kahler's disease is usually of medullary origin (bone plasmocytoma solitary or multiple and) sometimes extra bone [4] [5] [6] [7]. In these extra bone forms the orbital location is rarely described, justifying the interest of our present observation.

Thus, in the case of bone symptoms, with fever, anemia the presence of unilateral exophthalmos must lead to investigate kahler's disease.

The widest possible knowledge of the different clinical aspects should allow early diagnosis, and multidisciplinary management which will improve the prognosis of this severe disease.

\section{Observation}

It was about a 49 -year-old female patient who presented in her previous history a soft tissue swelling of the right thumb without bone involvement and that was followed for 6 months for a large major exophthalmos of the left eye (Figure 1). This exophthalmos was accompanied by headaches and thereafter acute bone pain at the spine and pelvis. This osteoarticular symptomatology justified hospitalization in our service. In hospitalization the patient presented a left subtrochanteric pathological fracture treated with osteosynthesis by intramedullary nail (Figure 2). The biopsy sample and histological analysis of the operative specimen during the intervention helped to find a monomorphic tumor proliferation made of plasmacytic cells with abundant eosinophilic cytoplasm and hyperchromic, nucleolated and eccentric nucleus with sometimes enlarged and monstrous nucleus and the existence of vast hemorrhagic area; and this aspect was compatible with bone plasmocytoma (Figure 3). A complementary chech-up balance showed a calcemia to $106 \mathrm{mmol} / \mathrm{l}$, a blood level of chloride to

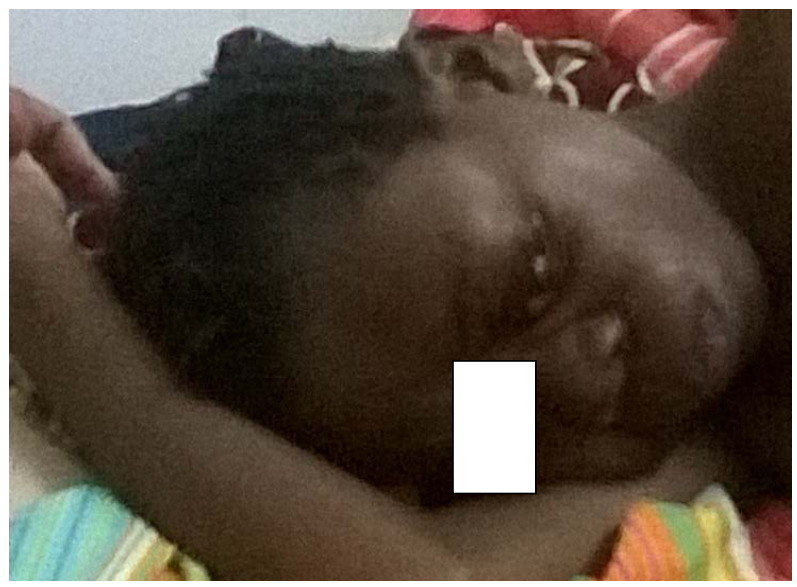

Figure 1. Major left Exophthalmos revealing a Kahler's disease. 


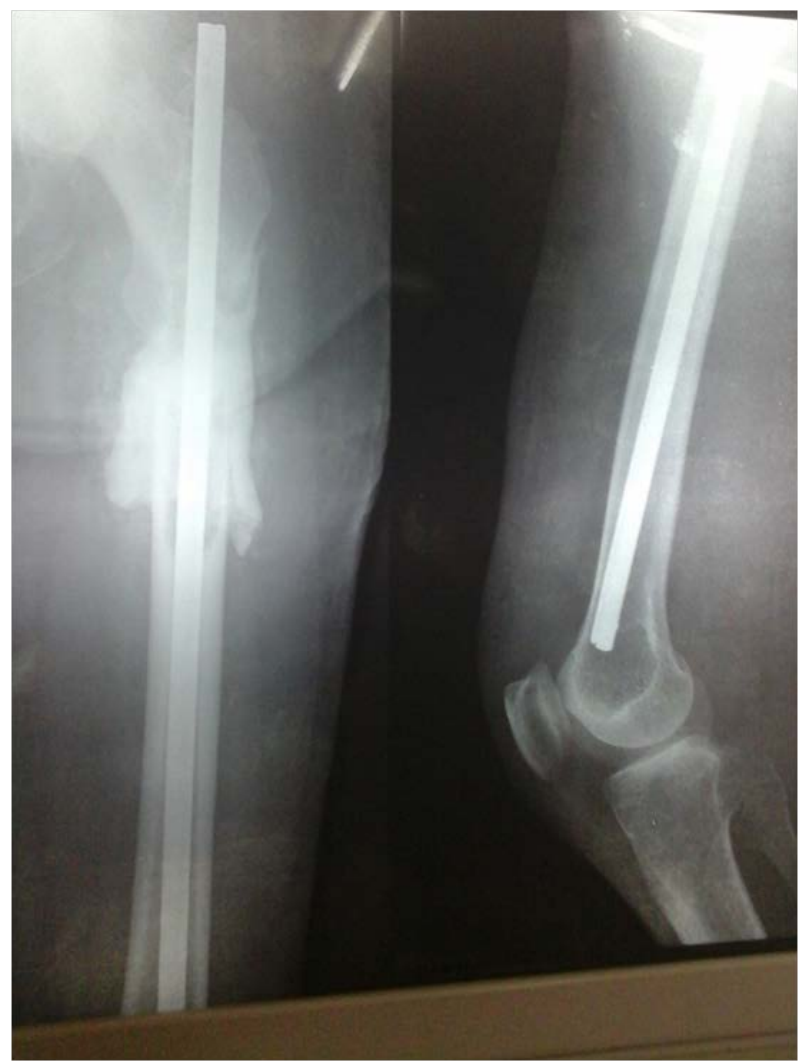

Figure 2. osteosynthesis by intramedullary nail.

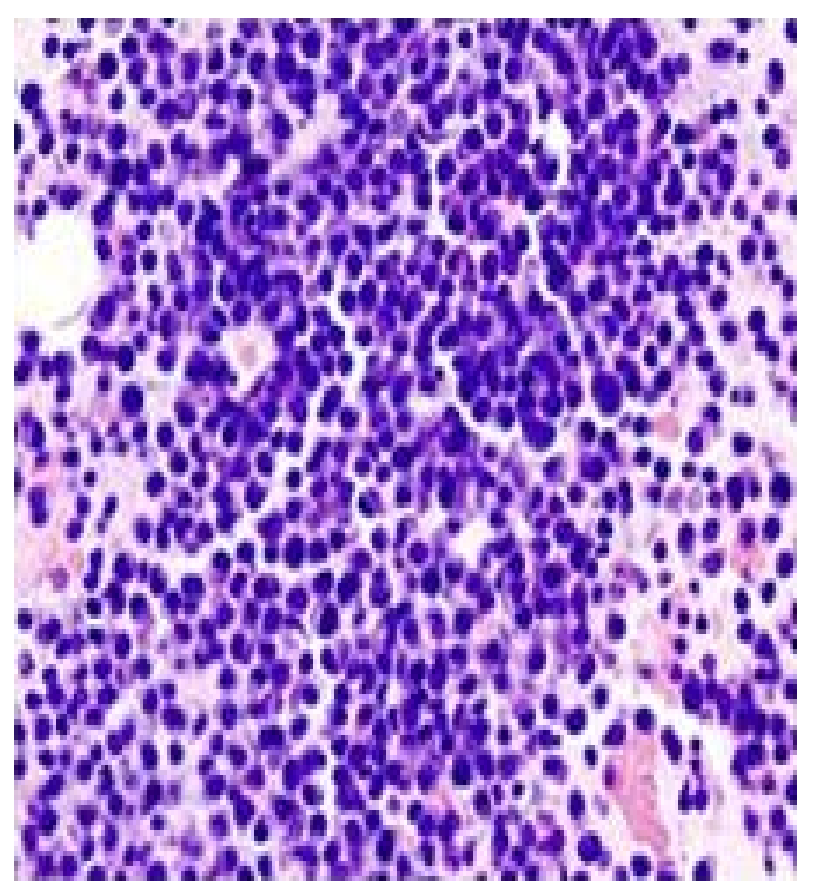

Figure 3. Monomorphic tumor proliferation made of plasmacytic cells with abundant eosinophilic cytoplasm and hyperchromic, nucleolated and eccentric nucleus with sometimes enlarged and monstrous nucleus and the existence of vast hemorrhagic area. 
$96 \mathrm{mmol} / \mathrm{l}$, potassium $5.36 \mathrm{mmol} / \mathrm{l}$ of sodium to $136 \mathrm{mmol} / \mathrm{l}$. The 24-hour proteinuria was $0.30 \mathrm{~g} / \mathrm{l}$ and signed renal impairment. The patient had anemia with a hemoglobin of $8.8 \mathrm{~g} / \mathrm{l}$. Tumour markers were normal; in particular the CA was 13.148 (0.000 to 35.000$)$, the ACE 2 were to $1.013 \mathrm{ng} / \mathrm{ml}(0.000$ to 10.000$)$ and CA 19-9 (CA19-9) were $5.029 \mathrm{IU} / \mathrm{ml}$ (0.000 to 35.000)

Imaging tests were also carried out in the assessment of the disease. CT scan of the entire skeleton found "gaps with cut-and-dried" to thorax, pelvis and the two massive trochanters (Figure 4, Figure 5). The chest radiograph was normal, abdominal CT found suspicious images of liver and lumbar spine.

Once diagnosed, the patient was referred to a specialized service for her management. But the evolution was quickly pejorative marked by a rapid deterioration of general condition, worsening of renal failure and death occurred in a table marked cachexia and this even before the start of treatment.

\section{Discussion}

Plasmocytomas are divided into three types: multiple myeloma or Kahler's disease which is characterized by multiple locations, solitary bone plasmocytoma and solitary extra bone plasmocytoma; both last ones which can progress to the first type whose prognosis is usually more annoying [1] [2] [3] [4] [5].

Epidemiologically, Kahler's disease is a rare cancer, representing $1 \%$ of human cancers and $10 \%$ of haematological malignancies [7] [8] [9].

Its incidence is 4.1/100,000 worldwide. It would be more common in Africans with an incidence of 9.5/00 100 inhabitants. Men are usually more affected than women and the age of predilection is beyond 50 years with a frequency peak at age 70 .

The usual location is medullary, in particular to the skull, at the spine and pelvis [1]-[7]. Extra medullary localizations have been described in particular the upper airway, gastro-duodenal tract, urogenital tract.

The orbital location is exceptional as outlined [8] [9]. Mouhdi published 1 case of unilateral exophthalmia in a 54 year old woman. She was followed for

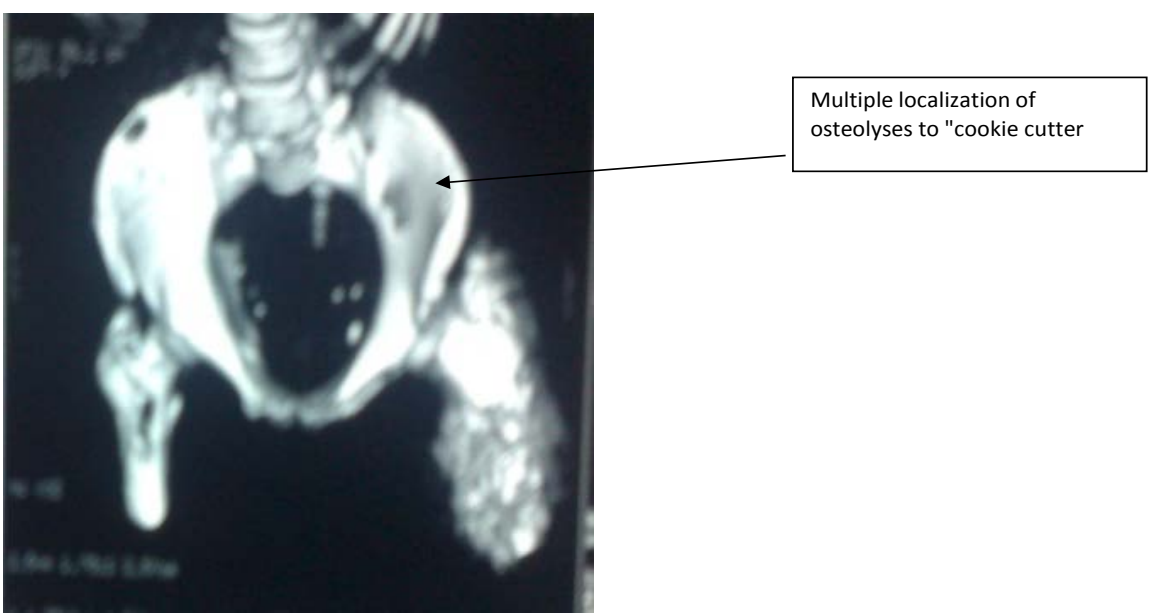

Figure 4. Multiple osteolysis cookie cutter to the pelvis, evocative a disease of Kahler. 


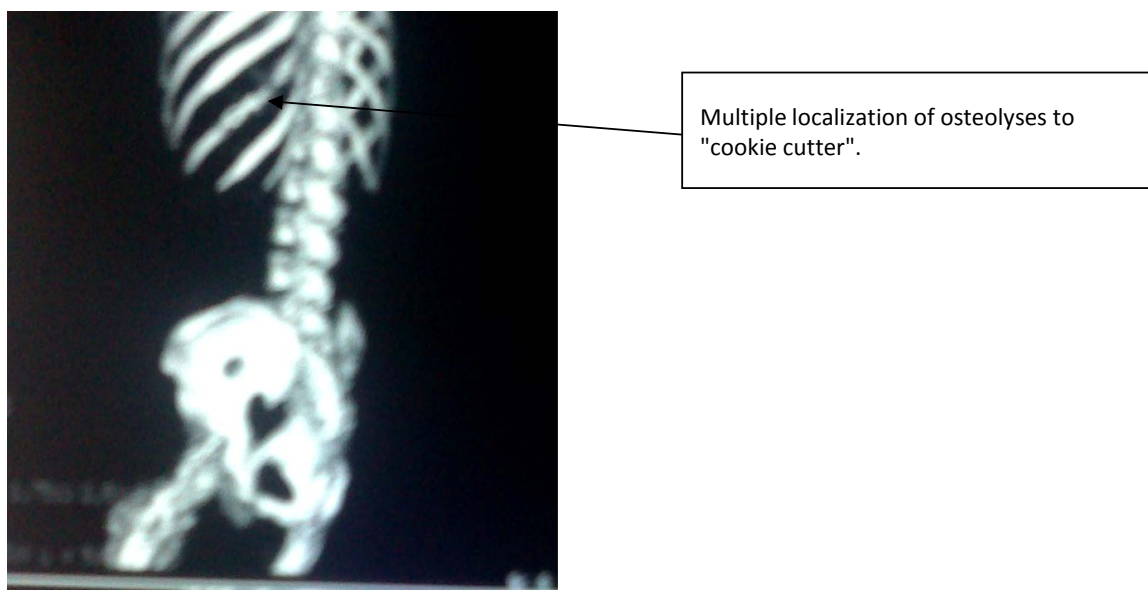

Figure 5. Multiple osteolysis to the thorax.

Kahler's disease since 3 years ago. The diagnosis was confirmed after biopsy of the tumor bud in the internal can thus she had received external radiation therapy at a dose of $30 \mathrm{~Gy}$, associated with a bolus of corticosteroids. The short-term evolution was marked by a decrease in exophthalmia and local edema, without any functional improvement [10]. The author also identified 50 cases of localization in world literature; which reflects the rarity of this location. In our case the clinical manifestation began with an eye location several months before the generalization, allowing saying that we are in the presence of extramedullary orbital location initially. The manifestation of other classically described signs that enabled the diagnosis of the disease Kahler.

On the positive diagnosis plan, it is based on a set of elements both clinical, biological, results of imaging and especially on pathological anatomy.

The clinic is generally dominated by the bone symptomatology in particular bone pain that is found in 7 of 10 patients or spontaneous fractures [4] [5] [6] [7] [8]. This bone symptomatology is also accompanied by anemia, significant weight loss, recurring infections. In our patient, this is a non-bone sign as exophthalmia that inaugurated the clinical picture.

The medical imagery has a particular interest in this disease because it allows suspecting the diagnosis.

In the front line, standard radiography that finds bone gaps "cookie cutter" characteristics. These lesions are best identified by computed tomography and magnetic resonance imaging.

A biological check-up generally finds hypercalcemia. But normal calcemia does not exclude the diagnosis. This is the case of our patient. SV is generally accelerated, there is a hyperproteinemia $>100 \mathrm{~g} /$ in protein electrophoresis; 24 hours proteinuria usually high means renal impairment.

But the diagnosis keystone remains the histology after biopsy puncture or better after highlighting a tumor proliferation monomorphic of plasmacytoid cells.

These different stages of diagnosis allow eliminating the other causes of radiological and biological disorder and in particular to make the differential diag- 
nosis of an exophthalmia. Thus, with these results we should discuss among others the disease of basedow, the infectious or traumatic causes [9] [10] [11] [12].

It is the diagnostic certainty that allows establishing an adequate treatment of the disease. This treatment is based on a multidisciplinary management between radiotherapy, chemotherapy and surgery. The chemotherapy is intended to eliminate or lower the plasma cell tumor mass as low as possible, treating the clinical signs in particular and thus enable a comfortable life of the patient.

Thus the chemotherapy achieves a cytoreductive therapy. The active chemotherapy combine MELPHALAN (M) or ALKERAN CYCLOPHOSPHAMINE + (C) + or ENDOXAN ANTHRACYCLINES (A) + corticosteroids (P) + radiotherapy.

But the conventional association is MP + VBAP/VMCP + VAD (vincristine, adriamycin, dexamethasone) The major risk of these products is myelodysplasia and secondary acute leukemia.

A symptomatic treatment is often associated and includes resuscitation correcting dehydration by alkaline hyperhydration (drinking 3 liters/day), a urate lowering treatment, correcting anemia by transfusions and treating any infection.

Despite a suitable treatment, the prognosis remains severe because the median survival was 3 years [12] [13] [14] [15]. Moreover, the orbital location would be worse prognosis especially when it spreads. In the case of our patient, the death occurred in the days following confirmation of the diagnosis.

\section{Conclusion}

Any isolated exophthalmos or accompanied by bone signs must always be considered a Kahler's disease and make undertake investigations in this direction. And it's the only condition for early treatment of the disease.

\section{References}

[1] Bataille, R. and Harousseau, J.L. (1997) Multiple Myeloma. The New England Journal of Medicine, 336, 1657-1664. https://doi.org/10.1056/NEJM199706053362307

[2] Damaj, G., Mohty, M., Vey, N., Dincan, E., Bouabdallah, R., Faucher, C., Stoppa, A.M. and Gastaut, J.A. (2004) Features of Extramedullary and Extraosseous Multiple Myeloma: A Report of 19 Patients from a Single Center. European Journal of Haematology, 73, 402-406. https://doi.org/10.1111/j.1600-0609.2004.00331.x

[3] Kapadia, S.B. (1980) Multiple Myeloma: A Clinicopathologic Study of 62 Consecutively Autopsied Cases. Medicine (Baltimore), 59, 380-392. https://doi.org/10.1097/00005792-198009000-00005

[4] Wax, M.K., Yun, K.J. and Omar, R.A. (1993) Extramedullary Plasmacytomas of the Head and Neck. Otolaryngology-Head and Neck Surgery, 109, 877-885. https://doi.org/10.1177/019459989310900517

[5] Patlas, M., Khalili, K., Dill-Macky, M.J. and Wilson, S.R. (2004) Spectrum of Imaging Findings in Abdominal Extraosseous Myeloma. American Journal of Roentge- 
nology, 183, 929-932. https://doi.org/10.2214/ajr.183.4.1830929

[6] Balliu, E., Casas, J.D., Barluenga, E. and Guasch, I. (2003) Multifocal Involvement of the Pancreas in Multiple Myeloma:sonographic, CT, and MR Imaging Findings. American Journal of Roentgenology, 180, 545-546.

https://doi.org/10.2214/ajr.180.2.1800545

[7] Alexiou, C., Kau, R.J., Dietzfelbinger, H., Kremer, M., Spiess, J.C., Schratzenstaller, B. and Arnold, W. (1999) Extramedullary Plasmacytoma: Tumor Occurrence and Therapeutic Concepts. Cancer, 85, 2305-2314.

https://doi.org/10.1002/(SICI)1097-0142(19990601)85:11<2305::AID-CNCR2>3.0.C $\underline{\mathrm{O} ; 2-3}$

[8] Dhermy, P., Limon, S., Dufier, J.L., Offret, G., Diebold, J., Reynes, M., et al. (1977) Atypical Orbital Localisation of a Myeloma. Non-Excretory Myeloma or Extramedullary Plasmocytoma. Archives of Ophthalmology, 37, 3-20.

[9] Adkins, J.W., Shields, J.A., Shields, C.L., Eagle, R.C.Jr., Flanagan, J.C. and Campanella, P.C. (1996) Plasmocytoma of the Eye and Orbit. International Ophthalmology, 20, 339-343.

[10] Mouhdi, H., Lezrek, M., Lachkar, R., Benchrif, Z., Bendouro, H., Benjaafar, N. and Kamouni, H. (2007) 631 La localisation orbitaire dans la maladie de Kahler. Journal français d'Ophtalmologie, 30, 2S329. https://doi.org/10.1016/S0181-5512(07)80444-X

[11] Kelly, S.P., Lloyd, I.C., Anderson, H., Joyce, P.W. and Pace-Balzan, A. (1991) Solitary Extramedullary Plasmacytoma of the Maxillary Antrum and Orbit Presenting as Acute Bacterial Orbital Cellulitis. British Journal of Ophthalmology, 75, 438-439. https://doi.org/10.1136/bjo.75.7.438

[12] Ezra, E., Mannor, G., Wright, J.E. and Rose, G.E. (1995) Inadequately Irradiated Solitary Extramedullary Plasmocytoma of the Orbit Requiring Exenteration. American Journal of Ophthalmology, 120, 803-805. https://doi.org/10.1016/S0002-9394(14)72739-4

[13] Kautzky, M., Susani, M., Steurer, M. and Youssefzadeh, S. (1993) Plasmacytoma of the Nose and Paranasal Sinuses with Intracranial and Orbital Extension. Laryngorhinootologie, 72, 352-355. https://doi.org/10.1055/s-2007-997916

[14] Boussen, H., El Khedim, A., Hachicha, S., et al. (1977) Le plasmocytome solitaire extra-médullaire du palais. À propos d'1 cas. Archives of Ophthalmology, 37, 3-20.

[15] Hassikou, H., Tabache, F., Safi, S., Laktaoui, A. and Hadri, L. (2007) Atteinte de l'orbite au cours d'un myélome à IgD Kappa. Journal français d'Ophtalmologie, 30, e6. https://doi.org/10.1016/S0181-5512(07)89573-8 